\title{
Organizational Complexity and Performance of Commercial Banks in Kenya
}

\author{
Ssemugenyi Fred (Ph.D) \\ Amboka Asumwa Agustine, (Ph.D cand) \\ Kazibwe Sophia (Ph.D) \\ Kampala International University
}

\begin{abstract}
The study sought to establish the effect of organizational complexity on performance of commercial banks in Kenya with a special focus on Kenya Commercial Bank. It had been hypothesized that the performance of commercial banks in Kenya is not affected by organizational complexity. To address this hypothesis, the study was thus guided by the following specific objectives; to establish the effect of technological/structural complexity on performance of commercial banks in Kenya. To assess the extent to which institutional/internal dimensions affect the performance of commercial banks in Kenya. To determine the effect of market/external characteristics on performance of commercial banks in Kenya. To explore the effect of social capital diversity on performance of commercial banks in Kenya. A descriptive survey design was adopted, complimented by a multiple linear regression in order to determine the effect of organizational complexity on the performance of commercial banks. Results revealed that, the features of complexity are ever more present in modern organizations and in environments in which they operate, trying to survive and be as competitive as possible. In the processes of the formal organizational structure, designed purposefully and with a plan, is going through a change due to complexity and the need for adaptation. As a result, there is a variety of new informal groups. At the same time, the intended structural changes and business process changes occur because of the perception that the leadership and senior organizational management have of the strategic situation. Most managers find it highly liberating to discover why there is a mismatch between their everyday lived reality and what conventional management 'wisdom' suggests should be happening. One of the great challenges any business or organization can face is how to deal with the unexpected. While traditional managerial practices such as planning are designed to manage unexpected threats, they often make things worse. Understanding the complex social reality of organisational life - arising from their own and everyone else's participation in it - provides a crucial first step in releasing them from the suffocating grip of the dominant management discourse. The study further found that complexity and organizational performance are two highly interlinked phenomena that create major dilemmas for organizations which express the fundamental challenges in coping with growing complexity in practice. The study also counsels that if increasing business environment complexity challenges organizations, the management of the organizations should carefully enhance the market-driven complexity of the organization and be aware of the valuecreating and non-value creating character of this category of organizational complexity. Without organizational performance the fruits of creativity will not be realized and adaptability will not be achieved. Thus these desirable behaviours in complex organizations could be facilitated by
\end{abstract}

an organization culture that encourages efficient operations. The complexity in the Organization calls for organizational adaptation in the form of well designed and yet spontaneous changes of structure, process, and strategy. The conditions of complexity require a different design, new leadership, and more advanced decision-making.

Keywords: Social capital diversity, institutional/internal dimensions, market/external characteristics, technological/structural complexity, expansion and organizational performance.

\section{INTRODUCTION}

Organizations are sites of situated social action more or less open both to explicitly organized and formal disciplinary knowledge such as marketing, production, and so on, and also to conversational practices embedded in the broad social fabric, such as gender, ethnic and other culturally defined social relations, themselves potential subjects for formally organized disciplinary knowledge. Accordingly, organizations build the structural basis for the cooperation of persons, material resources and information between the corporation and its environment, which consequently results in a certain mode of interaction between the environment and the corporation. As Stacey (2010) indicates, increased ambiguity and the rapid development of a largely unimpressionable business environment call for the managements' continual reevaluation of strategies and methods in order to cope with organizational complexity.

The idea of the complex system denotes presence of many independent entities, agents that behave in accordance with their objectives, and perform mutual interactions. Miller \& Page (2007) posit that complex systems are composed of numerous, varied, simultaneously interacting parts. In modern organizations, complexity as a characteristic feature occurs and grows when interdependence of the elements within the system becomes relevant. Organizational adaptation to environment with the option of changing its structure is an important phenomenon in both theory and practice of the organizational design and organizational changes. The number and diversity of the elements and their relationships as well as system-inherent dynamics constitute complexity. Complexity is a central theme in systems theory, which makes it possible to differentiate between simple, complex and very complex systems. 
Organisations consist of countless people interacting with each other continuously, both within and beyond the imaginary confines of any formally established 'organisational boundaries'. Complexity provides an explanatory framework of how organisations behave as well as how individuals and organisations interact, relate and evolve within a larger social ecosystem. Complexity also explains why interventions may have un-anticipated consequences (Holling, 2001). The intricate interrelationships of elements within a complex system give rise to multiple chains of dependencies. Systems theory plays an essential role in the development of complexity theory, with one mayor theoretical distinction being the system theory's relative disinterest in the identification of regularities with respect to complexity (Stacey, 2010b).

In recent years, Kenyan financial institutions were compelled to recapitalize and clear bad debts, scrubbing their Augean stables relatively clean. In the subsequent revival of their fortunes, they have been looking to leverage their investment and are setting their sights on expansions beyond the borders of their traditional niche markets so as to increase their customer base and spread their risks through diversification. Having expanded their capital base through the Nairobi Stock exchange, Kenyan banks have made an effort to set a footing into the Subregion, opening branches in South Sudan, Rwanda, Tanzania and Uganda. Their experience in expansion strategies at home prepared them for potential success, with a hope of injecting the much-needed competitiveness into East Africa's financial institutions and consequently resulting to their complexity.

\section{RESEARCH PROBLEM}

Organizations organically emerge out of the communication patterns that develop in the course of doing business and in response to the host of environmental variables in dynamically changing business landscapes. Organizations are instances of complex adaptive systems having many interacting subcomponents whose interactions yield complex behaviors. Such institutions can emerge from the bottom up as a result of feedback processes linking social actors to their environments. With increase in competition that most institutions are facing today, rewards will accrue to those who can read precisely what external force wants by continuously scanning the environment and delivering the greatest value to customer location.

Despite widespread agreement that organizational complexity creates big problems by making it hard to get things done, few executives have a realistic understanding of how complexity actually affects their own companies. Many executives allude to the institutional manifestations of complexity they personally experience: the number of countries the company operates in, for instance, or the number of brands or people they manage. By contrast, relatively few executives consider the forms of individual complexity that the vast majority of their employees face, for example poor processes, confusing role definitions, or unclear accountabilities.

Despite the enlargement absorbing real and substantial costs, and considering Ashmos (2006) conclusion that the clarity of organizational objectives in terms of expansion has led to an increased emphasis on the evaluation of return on investment, Carlisle \& McMillan (2006) observe that systematic evaluation rarely occurs within complex organizations. Making causal connections between investment in expansion, and future management performance and organization success is externally difficult. Such a scenario highlights the difficulty in establishing a statistical link between the incidence of expansion and company performance. Organizational complexity in the banking industry therefore demands that firms should have effective systems in place to counter unpredictable events that can sustain their operations and minimize the risks involved. It is in this light that the study sought to establish the impacts of organizational complexity on performance of commercial banks in Kenya with a special focus on Kenya Commercial Bank.

\section{RESEARCH OBJECTIVES}

The main objective of this study was to investigate the impacts of organizational complexity on performance of commercial banks in Kenya with a special focus on Kenya Commercial Bank.

The specific objectives of this study were:

i. To establish the effect of technological/structural complexity on performance of commercial banks in Kenya

ii. To assess the extent to which institutional/internal dimensions affect the performance of commercial banks in Kenya

iii. To determine the effect of market/external characteristics on performance of commercial banks in Kenya

iv. To explore the effect of social capital diversity on performance of commercial banks in Kenya

\section{CONCEPTUAL FRAMEWORK}

An overview of the conceptual framework in Figure 1, illustrates the underlying variable relationships as used in this paper. In this study, the independent variables are institutional/internal dimensions, market/external characteristics, technological/structural complexity and social capital diversity while the dependent variable is organizational performance. 


\section{Independent Variables}

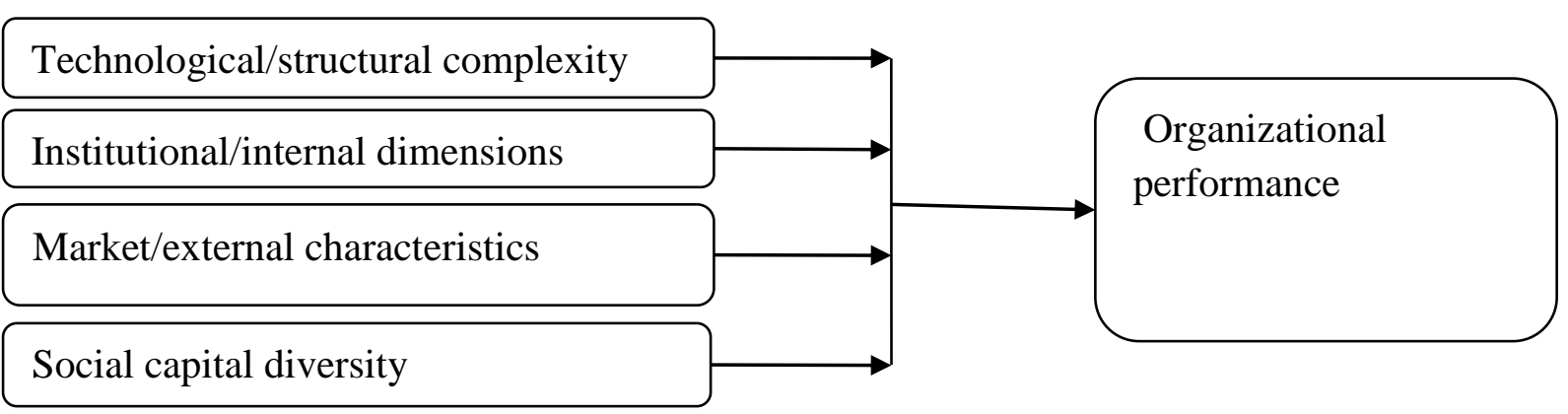

Figure 1: Organizational Complexity and Performance of the Kenya Commercial Bank Methodology

This research problem was studied through the use of a descriptive research design. The target population of this study was the 100 top, middle and lower level management staff working at the head offices of KCB in Nairobi. A sample of $50 \%$ (50 responding staff) was drawn from the staff working in the bank using stratified random sampling technique. This implied that this population would have diverse socio-economic backgrounds that were relevant to this study. Primary data was collected using a selfadministered questionnaire. Data collected was largely quantitative and it was analyzed by descriptive analysis techniques. The descriptive statistical tools such as SPSS helped the researcher to describe the data and determine the extent to which it has been used.

\section{FINDINGS}

From the study, technological/structural complexity influences performance of the Bank to a great extent. The level of technological innovation and use of modern technology affects competitiveness, customer satisfaction, product diversification and process improvement which in turn affect the performance of organizations with complex systems and networks like the KCB.

The study established that a complex adaptive system in $\mathrm{KCB}$ is made up of a number of subsystems and sub-subsystems. Each of these subsystems execute distinct functions and respond to different clientele, while requiring different resources and a certain amount of stability to deliver the requested performance. Accordingly, institutional factors determine the success of geographical expansion of banks to a very great extent

The study found that market/external characteristics determine the organizational performance of the Bank to a very great extent. Number and relative strength of buyers and sellers affects the performance of the Bank as well as level and forms of competition and extent of product differentiation. The bank undertakes a comprehensive and critical review of their present financial standing and future prospects in the expected cash inflows before expanding a business into a new area, the bank undertakes geographical expansion to maximize the benefits from expansion by implementing a series of relevant strategies and the bank relies on beliefs that the industry or market is a good fit with its existing operations.

The study further found that the organization promotes mutual trust and respect among employees through its core values to define what the organization stands for, creating teamwork through committees team building cross and functional networking to create synergies, the organization prepares the staff for higher future roles through training and development, experience, acting on appointment, strategic transfer and through mentorship programs and the organization has preference for recruitment candidates who hold or have held leadership positions.

Table 1: Multiple Regression Analysis

\begin{tabular}{|c|c|c|c|c|c|}
\hline & \multicolumn{2}{|c|}{ Unstandardized Coefficients } & \multirow{2}{*}{$\begin{array}{l}\text { Standardized } \\
\text { Coefficients } \\
\text { Beta }\end{array}$} & \multirow[t]{2}{*}{$\mathbf{t}$} & \multirow[t]{2}{*}{ Sig. } \\
\hline & B & Std. Error & & & \\
\hline (Constant) & 3.432 & .412 & & 4.009 & 0.00000 \\
\hline Institutional/internal dimensions & 0.318 & .084 & .023 & 0.358 & 0.00452 \\
\hline Market/external characteristics & 0.553 & .146 & 0.330 & 1.379 & 0.00411 \\
\hline $\begin{array}{l}\text { Technological/structural } \\
\text { complexity }\end{array}$ & 0.474 & .064 & 0.314 & 1.284 & 0.00414 \\
\hline Social capital diversity & 0.248 & .107 & .145 & 0.263 & 0.00456 \\
\hline
\end{tabular}

Dependent Variable: Performance of the Kenya Commercial Bank

The regression equation $\left(\mathbf{Y}=\boldsymbol{\beta}_{\mathbf{0}}+\boldsymbol{\beta}_{1} \mathbf{X}_{1}+\boldsymbol{\beta}_{2} \mathbf{X}_{2}+\boldsymbol{\beta}_{3} \mathbf{X}_{3}+\boldsymbol{\beta}_{4} \mathbf{X}_{4}+\boldsymbol{\beta}_{5} \mathbf{X}_{5}+\boldsymbol{\beta}_{6} \mathbf{X}_{6}\right)$ now becomes:

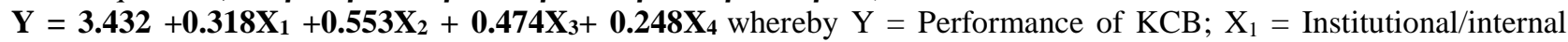
dimensions, $\mathrm{X}_{2}=$ Market/external characteristics, $\mathrm{X}_{3}=$ technological/structural complexity and $\mathrm{X}_{4}=$ Social capital diversity 
According to the regression equation established, taking all factors (institutional/internal dimensions, market/external characteristics, technological/structural complexity and social capital diversity) constant at zero, the performance of KCB realized would be 3.432 as shown by the Beta Value. The study results showed that taking all other independent variables at zero, a unit increase in institutional/internal dimensions will lead to a 0.318 increase in Performance of KCB. A unit increase in market/external characteristics will lead to a 0.553 increase in Performance of KCB. In addition, the beta value recorded for technological/structural complexity showed that a unit increase in market focus will lead to a 0.474 increase in Performance of $\mathrm{KCB}$. From the regression model the Beta value recorded showed that a unit increase in technological/structural complexity would lead to 0.248 increase on Performance of KCB.

\section{DISCUSSIONS}

The behavior of complex systems is non-deterministic, since a small change of one or two parameters can drastically change the behavior of the whole system. Similarly, the whole is different than the sum of its parts. Compared to traditional management standards, selforganizational behavior seems to be disorganized as behavioral patterns and decisions emerge from the situational context. The complexity absorption capabilities increases if the organization incorporates additional complexity related to the market and customer needs in one area, while simultaneously reducing complexity in other areas to hold the system in balance at the edge of chaos.

Technological and structure complexity are the two types of internal complexity. Technological complexity creates the need for highly skilled problem solving to achieve the goals of the project using the technological tools available. But it may not be possible to solve these problems and achieve the project goals with the chosen technology. Structural complexity creates the need for carefully chosen responses to unanticipated environmental change or workbased exceptions because the structurally complex project is difficult to redirect, once it is underway. In addition, small influences, such as a small delay of a critical part, can have large influences as they roll through the large and highly complex system. Thus, internal sources of project complexity may not always be adequately addressed by the creative, learning, and adaptive responses facilitated by adaptive and enabling leadership.

The internal organizational arrangements are based on a more mechanistic understanding of the world and include high levels of control, centralization and formalization. The strength in managing complexity is based on global guidance and simple principles of giving a common sense and vision to dissimilar organizational parts. Companies with a complexity reduction strategy simplify both marketdriven and organization-driven complexity when focusing on specific customer segments. They decide to fulfill only well-chosen market demands and focus on this limited scope.
In addition, all drivers of market-driven complexity have a positive impact on organizational performance in low complex organizations. Consequently, the increase of complexity can easier be managed, if the organization starts from a low level of complexity. The approach to managing complexity depends on the current situation at hand, and the success of the organization depends on the capabilities of the company to manage the six fundamental drivers of market-driven complexity: product diversification, globalization, organizational change, depth and breadth, technological intensity, and size.

\section{CONCLUSIONS}

The study concludes that technological and structural compatibility influence organizational performance of complex organizations. The study deduced that compatibility of the different systems causes a challenge in management of complex organizations, roadblocks to collaboration between widespread departments also affects the performance of expanded organizations, installation of new systems poses financial challenge in the change management, mismatch between software tools and company needs challenges performance in the institution and that lack of proper knowledge poses a challenge in performance of complex organizations.

The study also concludes that institutional/internal dimensions determine the performance of complex banks. As such the various aspects of institutional/internal dimensions that affect performance of the banks include market/customer base, governance, funding, work force as well as skills and knowledge. In addition, product introduction and product/service quality of the Company are attributable to negative effects of complexity and dynamism, and positive effect of munificence.

The study concludes that market/external characteristics are a key determinant for the performance of complex commercial banks. This is because various market structures like number and relative strength of buyers and sellers as well as level and forms of competition, government regulations and extent of product differentiation were found to affect the performance of banks.

The study also concludes that social capital diversity affects the mutual trust and respect among employees through its core values to define what the organization stands for, creating teamwork through committees team building cross and functional networking to create synergies. The organization prepares the staff for higher future roles through training and development, experience, acting on appointment, strategic transfer and through mentorship programs.

\section{RECOMMENDATIONS}

The study recommends that if increasing business environment complexity challenges organizations, the management of the organizations should carefully enhance the market-driven complexity of the organization and be aware of the value-creating and non-value creating 
character of this category of organizational complexity. Furthermore, to ensure success, they should reduce organization-driven complexity.

Due to the positive influence of the drivers of marketdriven complexity, the empirical results also confirm that concentrating on core competencies is not a dominant strategy in business environments with growing complexity These desirable behaviors in complex adaptive systems; such as creativity, learning and adaptability, are closely associated with organizational performance. Without organizational performance the fruits of creativity will not be realized and adaptability will not be achieved. Thus these desirable behaviours in complex organizations could be facilitated by an organization culture that encourages efficient operations.

The complexity in the Organization calls for organizational adaptation in the form of well designed and yet spontaneous changes of structure, process, and strategy. The conditions of complexity require a different design, new leadership, and more advanced decision-making. Adaptation of the Organization to its environment is linked with the practice of organizational changes. Generally, organizational change is motivated the move the ongoing situation towards certain desired situation in the future that is aimed at increased efficiency and competitiveness.

To enhance the ability of complex organizations, organization such as KCB must work on its flexibility in terms of design solution. The adaptive business intelligence system partly steps up the level of overall adaptability. For a more successful organizational performance improvements must encompass the entire organizational learning and doing cycle and all segments and levels - all the way to the action itself - operative, tactical and strategic.

\section{REFERENCES}

[1] Ashmos, D. P., (2000), Organizational Responses to Complexity - The Effect on Organizational Performance, Journal of Organizational Change Management. Vol. 27 No.2, pp.25-6.

[2] Birkinshaw, J. and Heywood, S. (2010) Putting Organizational Complexity in its Place. McKinsey and Co. Insights \& Publications, May 2010.

[3] Carlisle, Y. and McMillan, E. (2006), Innovation in Organizations from a Complex Adaptive Systems Perspective, in: Emergence: Complexity and Organization, $8,1,2-9$.

[4] Holling, C.S. (2001). Understanding the Complexity of Economic, Ecological, and Social Systems. Ecosystems 4, 390-405.

[5] Miller, J.H. and Page, S.E. (2007). Complex Adaptive Systems. Princeton University Press.

[6] Stacey, R.D. (2010a). Complexity and Organizational Reality. Routledge

[7] Stacey, R.D. (2010b). Strategic Management and Organisational Dynamics, 6 Ed. Financial Times/ Prentice Hall. 